\title{
Effect of Tar Epoxy coating on initial water absorption of concrete surface
}

\author{
Leena Jaffer Sedeeq ${ }^{1}$ and Khaild Mohammed Shaheen ${ }^{2}$ \\ \{Leena.j.shamdeen@gmail.com ${ }^{1}$, khmshaheen@gmail.com ${ }^{2}$ \} \\ Technical Institute/Mosul, Northern Technical University, Iraq ${ }^{1,2}$
}

\begin{abstract}
Waterproofing is an essential property to be considered in concrete structures due to the many serious consequences of dampness caused by the ingress of water into the concrete. This paper explores the ability of decreasing water absorption of concrete surfaces by utilizing tar epoxy. The first part of the study deals with the initial surface absorption (ISA) of water by the coated and uncoated concrete specimens. The blending proportion of tar: epoxy of 1:1, accomplished $100 \%$ waterproofing for the concrete surfaces. The effect of an acidic solution of $\mathrm{pH}$ of 3.5 on the coated and uncoated concrete specimens was studied in the second part. The experimental results revealed that the surface of concrete specimens that coated deteriorate less than the uncoated ones when exposed to sulfuric acid solution of $\mathrm{pH}$ of 3.5 .
\end{abstract}

Keywords: primer, Tar Epoxy, Initial Surface Absorption, Acidic solutions, Waterproofing.

\section{Introduction}

Like some other material, concrete is dependent upon crumbling because of various variables. Among the elements results in the weakening of concrete strength due to humidity, water absorption, concrete porosity, corrosion of reinforcement, and climatic conditions, particularly acid rain. It is important to have some designed process methodology to support the life cycle of the material without huge decay $[1,2]$. Entrance of water is a significant factor that upgrades the decay of concrete $[1,3]$. The concrete surface is the first line of defense against the entrance of water and forceful operators into the concrete. There is an expanding attention to this subject because of its serious results on the mechanical properties of the concrete and execution of the related structures. The initial surface absorption test (ISAT) is the laboratory test that is normally utilized in assessing the magnitude of water entrance into concrete. The details of the test are introduced in B.S. 1881: Part 5: 1970, [4]. Prolonging the administration life of concrete structures using of waterproof coatings has been underscored [5, 6]. Additionally, the exhibition of the coated concrete against chemically aggressive environments is commonly better than the performance of the uncoated concrete [7]. This study centres around lessening the penetration of water into concrete by utilizing many blending proportions of tar: epoxy and level of their affectedness by the activity of acidic solution 
The experimental part of the present study was conducted in the laboratories of the Technical College of Mosul within the period of December 2012 - July 2013, at room temperature. The waterproof coatings were supplied by Al-Fadox Group Company, Jordan. The Company is concerned with polymer industry, building construction chemicals, decoration requirements, and materials used to repair construction defects. In fact, the researcher was faced with many difficulties among which was the lack of sufficient related literature. Water proofing materials are gaining an increased interest in different types of buildings in Iraq. So it was decided to go through this subject and test the effectiveness of certain concrete surface sealants on the local concrete under local environmental conditions.

\section{Methodology}

A. Manufacturing the initial surface absorption test apparatus:

The initial phase in the trial work was the creation of an apparatus for the ISAT, appeared in Figure 1. The gadget was manufactured based on BS 1881: Parts 5:1970 [4]. Schematic diagram of the ISAT apparatus shown in Figure 2.

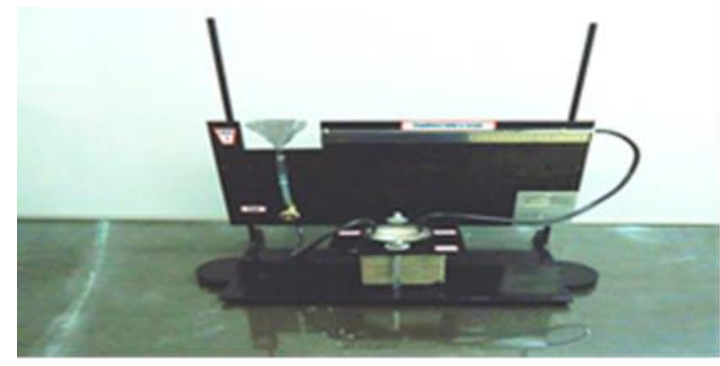

Figure.1. Initial Surface Absorbtion Test Apparatus.

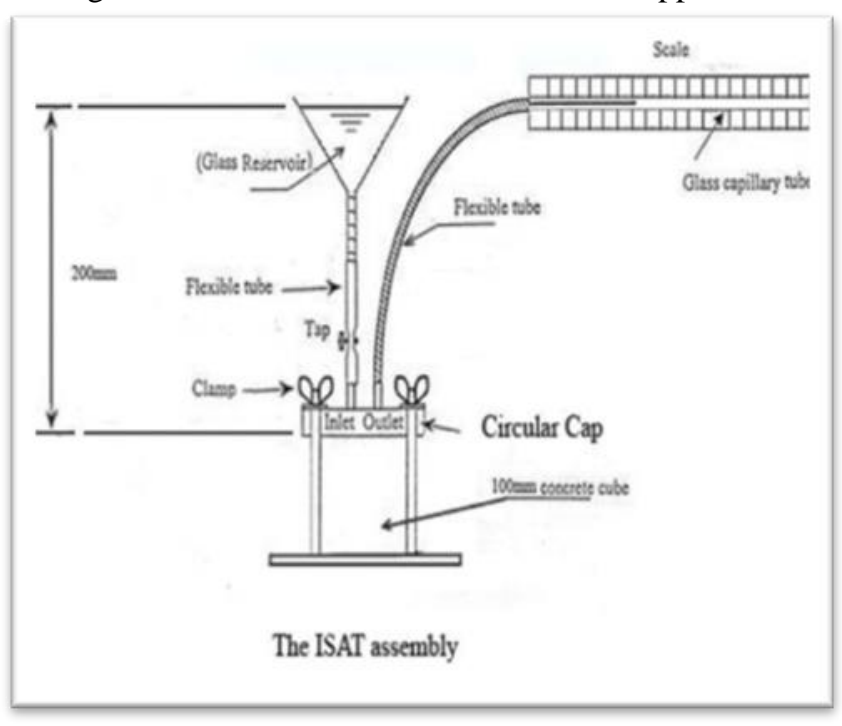

Figure.2 . Schematic Diagram of The ISAT Apparatus. 
Components of the ISAT Apparatus: Frame: The frame of the apparatus is made of iron.

1. Cap: The cap provides a water contact area of $5000 \mathrm{~mm} 2$ with the concrete surface to be tested. It is made of transparent stiff acrylic which allows observing the cap filling up with water and the air being displaced. An inlet and outlet tubes are fixed into the cap. These tubes connect the reservoir to the cap and the capillary tube. The outlet is so as to allow all trapped air to flow out.

2. Glass Reservoir: The reservoir has the shape of a funnel made of glass connected to the inlet of the cap by a flexible tube onto which a control tap is fixed.

3. Capillary tube and scale: This is a $350 \mathrm{~mm}$ long glass capillary tube, with a bore of 2 $\mathrm{mm}$ diameter. These dimensions are within the limits specified by BS: 1881Part 5-1970 [4]. One end of the capillary tube protrudes beyond the end of the scale, and the other is connected through a flexible tube to the outlet of the cap.

Table 1. LIST OF ABBREVIATIONS

\begin{tabular}{cc}
\hline Description & Abbreviation \\
\hline B.S & British Standard \\
\hline ISA & Initial surface absorption \\
\hline ISAT & Initial surface absorption test \\
\hline w/c & Water to cement ratio \\
\hline $\mathrm{m} 1$ & $\begin{array}{c}\text { The specimen's weight before } \\
\text { immersion in acid. }\end{array}$ \\
\hline $\mathrm{m} 2$ & $\begin{array}{c}\text { The specimen's weight after } \\
\text { immersion in acid. }\end{array}$ \\
\hline
\end{tabular}

\section{B. Ingredients Mixture of the Concrete \\ 1. Gravel:}

The gravel utilized was river bed rock got from the Tigris River north of Iraq. A $20 \mathrm{~mm}$ size is used in the test. Table 2 presents the details of the gravel based on specifications No.45/1984 [8].

Table 2. Sieve Analysis of Gravel

\begin{tabular}{ccc}
\hline $\begin{array}{c}\text { Sieve Size } \\
\text { S. }(\mathrm{mm})\end{array}$ & $\begin{array}{c}\text { Weight Passing } \\
(\%)\end{array}$ & $\begin{array}{c}\text { Total limits (Iraqi Standard } \\
\text { Specification No.45/1984) }\end{array}$ \\
\hline 20 & 98 & $95-100$ \\
\hline 10 & 43 & $30-60$ \\
\hline 5 & 0.45 & $0-10$ \\
\hline
\end{tabular}




\section{The Sand}

The sand utilized in this paper was normal sand provided from Kanhash district (Mosul). This sand matches the specifications standard No.45/ 1984 limits [8], and shown in Table (3) based on fine aggregate (Sand).

Table 3. Sand Sieve Analysis

\begin{tabular}{ccc}
\hline $\begin{array}{c}\text { Sieve Size } \\
\text { B.S. }\end{array}$ & $\begin{array}{c}\text { Weight } \\
\text { Passing } \\
(\%)\end{array}$ & $\begin{array}{c}\text { Specification } \\
\text { No.45/1984) }\end{array}$ \\
\hline $4.75 \mathrm{~mm}$ & 100 & $90-100$ \\
\hline $2.36 \mathrm{~mm}$ & 81 & $75-100$ \\
\hline $1.18 \mathrm{~mm}$ & 66.33 & $55-90$ \\
\hline $600 \mu$ & 52.3 & $35-59$ \\
\hline $300 \mu$ & 23.5 & $8-30$ \\
\hline $150 \mu$ & 6.7 & $0-10$ \\
\hline
\end{tabular}

\section{Cement:}

The cement material are considered from Portland produced by Badoosh Factory (Mosul) as detailed in [9].

Table 4. The cement utilized in this investigation

\begin{tabular}{cccccc}
\hline Main Oxide & Cao & Fe2o3 & Al2o3 & So3 & Mgo \\
\hline$\%$ & 63.1 & 2.67 & 5.89 & 2.6 & 3.62 \\
\hline $\begin{array}{c}\text { I.S.S. } \\
\text { No.5/1984 }\end{array}$ & - & - & - & Max. 2.8\% & Max. \\
\hline
\end{tabular}

\section{Coating Materials:}

1. The Primer: It is a fluid specialist applied to the concrete surface liberated from oil, grease, and any foreign materials to avoid separation of coating. Figures 2 show the primer used in this study.

2. Tar Epoxy: Is either an amine or polyamide adjusted with tar pitch resin to achieve a highchemical resistance film and fantastic water opposition. Technical Data Sheet for tar epoxy is illustrated in Table (5)

Table 5. Technical Data Sheet for tar epoxy

\begin{tabular}{cc}
\hline Physical Properties & Value \\
\hline Elongation $\%$ & 360 \\
\hline Specific gravity & $1.5-1.7$ \\
\hline
\end{tabular}




\begin{tabular}{cc}
\hline$(\mathrm{gm} / \mathrm{cm} 3)$ & \\
\hline Viscosity $(\mathrm{Cp})$ & $2150-3100$ \\
\hline Shelf life (months) & 24 \\
\hline $\begin{array}{c}\text { Tensile strength } \\
(\mathrm{MPa})\end{array}$ & 60 \\
\hline
\end{tabular}

\section{The Mix Proportions of Concrete:}

For 28 days' age, we used $35 \mathrm{MPa}$ based on British mix standards method for a volume density of cement $380 \mathrm{~kg} / \mathrm{m} 3$.

\section{E. Blending, Casting, and Curing of Concrete Specimens:}

Blender of a limit of 134 litres utilized for blending the elements of the concrete. The inside surface of the blender was cleaned and dampened before setting the materials based on ASTM C192 [10]. Curing was accomplished according to ASTM C511 [11].

\section{F. Preparation of Concrete Specimens Surface:}

The coating layer depends on the application and services considered that defines the life cycle [11]. Cleaning process should take place including care of drying the surface since dampness will affect the bond of the covering layer.

\section{COATINGS APPLICATION :}

1. Primer Application: After getting ready concrete specimens surface, the surface was covered with thin coatings layer using roller brush.

2. Tar Epoxy Application: The surfaces covered with the utilized material based on tar blended with epoxy for two ratios. The ratios considered are 1:0.5 and 1:1, for which the coating parameters are illustrated in Table 6.

Table 6. Concrete samples specifications

\begin{aligned} & \hline sample Description \\ & \hline A Concrete samples without coating \\ & \hline B $\begin{array}{l}\text { Coated concrete samples with tar:epoxy with } \\ \text { ratio 1:0.5 }\end{array} \\ &$\hline C $\begin{array}{l}\text { Coated concrete samples with tar:epoxy with } \\ \text { ratio 1:1 }\end{array} \\ &$\hline\end{aligned}


The process of testing: three tests were carried out over concrete samples and the mean values were computed as summarized in Table 7 .

Table 7. Concrete Test

\begin{tabular}{lll}
\hline Standards & $\begin{array}{l}\text { Shape and dimension } \\
\text { of molds used }\end{array}$ & Test \\
\hline BS 1881: Parts 5:1970 [3] & Cube: $100 \mathrm{~mm} \times 100 \mathrm{~mm} \times 100 \mathrm{~mm}$. & $\begin{array}{l}\text { Initial surface } \\
\text { absorption test (ISAT) }\end{array}$ \\
\hline & Cube: $100 \mathrm{~mm} \times 100 \mathrm{~mm} \times 100 \mathrm{~mm}$. & Resistance to acid attack \\
\hline
\end{tabular}




\section{RESULTS}

\section{Initial surface absorption test (ISAT):}

The ISA was applied to the coated and uncoated concrete specimens for four successive periods of time that are 10, 30,60 and 120 minutes according to B.S:1881Part 5-1970 [4]. Throughout the test the head of the water above the surface of the specimens was kept around $200 \mathrm{~mm}$. As a beginning, the casketed cap was clamped on to the sample. Then, the water into the reservoir was let to run into the cap and out until no air was left in it. The water in the capillary tube was allowed to overflow to ensure that no air was left in the tube. The outcome of the Initial surface absorption test for the concrete specimen A is depicted in Figure 3.

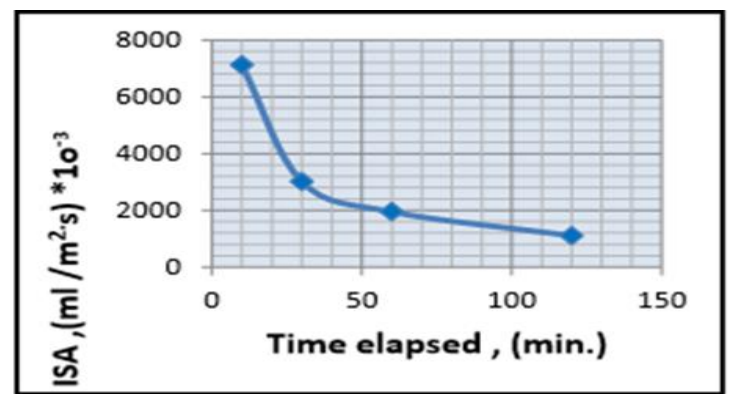

Figure.3 . Variations of ISA using A data for 28 Days

For the ratios of 1:0.5 and 1:1 of tar:epoxy, the variations of ISA are presented in Figures 4 and 5, individually. From Figure 5 for 1:1 ration brought zero ISA values at all exposure times.

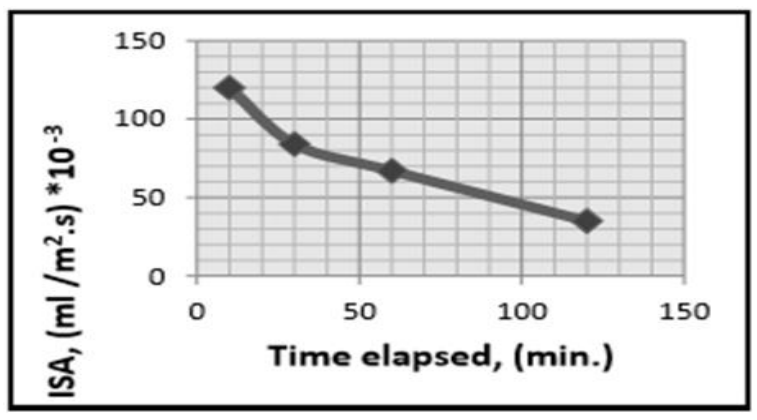

Figure 4. Variations of ISA using B data for 28 Days 


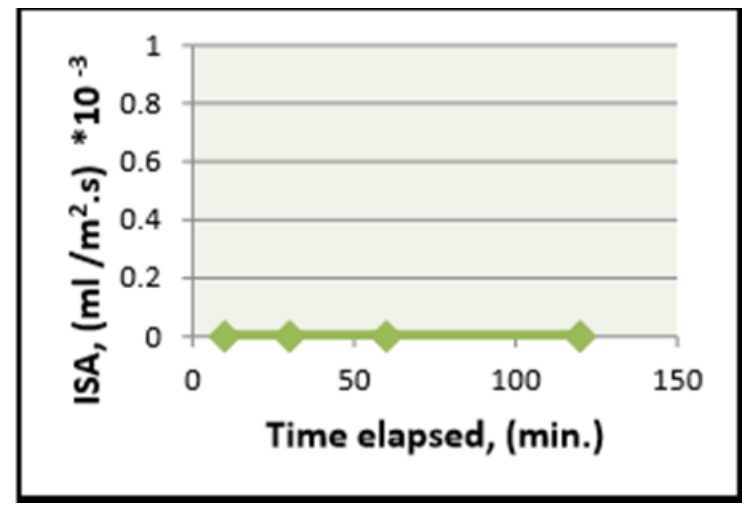

Figure 5. Variations of ISA using C data for 28 Days

2. Weight Loss (WL): The resistance to attack of sulfuric acid solution of $\mathrm{pH}=3.5$ was assessed by determining the weight loss of the coated and the uncoated concrete specimens. The weight loss for the specimens was determined after contact in the acid solution for periods of 56, 90and 120, days respectively. The specimens were washed by water immediately after their removal and then kept the specimens for 72 hours to be dry. After that, the specimens were weighted to calculate their mass loss by using a balance of accuracy of $0.05 \mathrm{gm}$. The average weight loss of three specimens was recorded for each of the indicated immersion period. Aftereffects of weight reduction determined as WL $(\%)=[(\mathrm{m} 1-\mathrm{m} 2) / \mathrm{m} 1] \mathrm{X} 100$ showed in Figures 6-8. The above outcomes show the WL with coated concrete sample using sulphuric acid was not as the uncoated sample. It implies all waterproofing coatings utilized from the activity of the acidic solution yet with changing degrees.

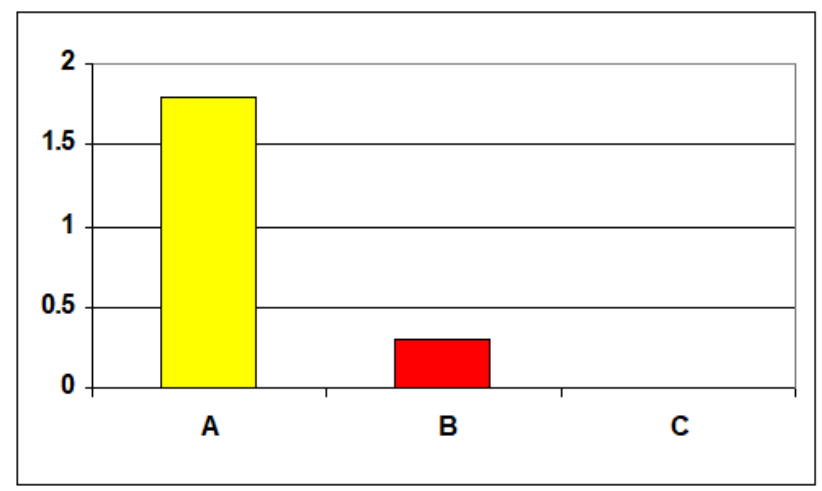

Figure 6. The $\%$ WL for 56 Days 


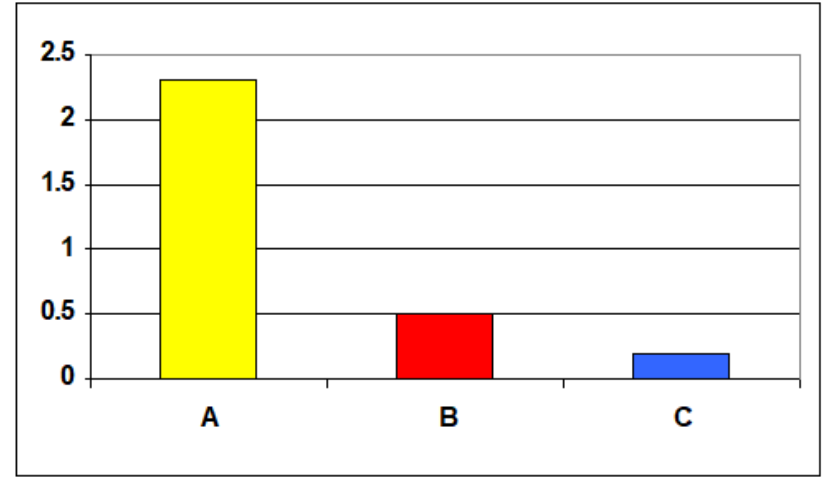

Figure7. The $\%$ of WL for 90 Days

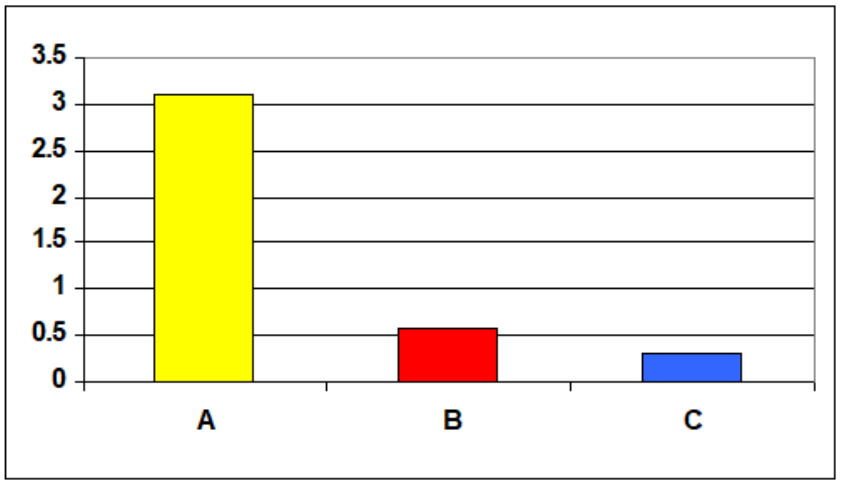

Figure 8 . The $\%$ of WL for 120 Days

\section{CONCLUSIONS}

Based on the outcomes of the tests, we concluded the following:

- Coating the surface of concrete with tar epoxy decreased the water absorption through the concrete surface.

- ISA linearly reduced the exposure time for samples under considerations.

- At all presentation times, 1:1 ratio Tar:epoxy produces zero ISA components.

- The performance of the coated concrete against acidic solution was generally better than that of the uncoated concrete.

\section{Acknowledgments.}


The authors thank the Northern technical University /Technical Institue / Mosul for providing facilities to complete this research

\section{References}

[1] Khalid M. Shaheen. Leena J Sedeeq "Concrete surface selants: a comparative study “ JOurnal University of Duhok, VOL. 17 NO. 1 (PURE and Eng. Science ), Pp(119-125), 2014

[2] Neville A. M., Brooks J. J., (2010), "Concrete Technology", 2nd edition, London: Pearson.

[3] Richardson, M., (2002)," Fundamentals of Durable Reinforced Concrete ", London and New York: Spon press.

[4] British Standards B.S. 1881: Part 5: 1970, Standards test method for determining the initial surface absorption of concrete.

[5] Vera, R., Apablaza, J., Carvajal, A. and Vera, E., "Effect of Surface Coatings in the Corrosion of Reinforced Concrete in Acid Environments", International Journal of Electrochemical Science, pp. 11832-11846, 2013.

[6] Orlowsky, j, Raupach, M. Baias, M. and Blümich, B., "Application of the NMRtechnique to concrete-coatings" Concrete Repair, Rehabilitation and Retrofitting Taylor \& Francis Group, London, ISBN 978-0-415-46850-3, 2009

[7] Aguiar, J., Camoes, A, and Moreira, P.,"Coating for Concrete Protection against Aggressive Environments", Journal of Advanced Technology Vol.6.No.1,PP. 243250,2008 .

[8] Iraqi Standard Specification No.45, "sieve analysis of aggregate", 2004.

[9] Cement Badoosh factory, Personal communication.

[10] American Society for Testing and Materials. ASTM C 192-98, Standard test method for curing concrete test specimens in the laboratory. ASTM Standards 2004.

[11] American Society for Testing and Materials. ASTM C 511-98, Standard test method for casting concrete test specimens in the laboratory. ASTM Standards 2004.

[12] Petrie .E, (2000), "Handbook of Adhesives and Sealants", McGraw Hill.

[13] American Society for Testing and Materials. ASTM C 143-98, Standard test method for slump of hydraulic-cement concrete. Standards 2004.

[14] British Standard B.S., "Method for Determination of compressive strength of concrete cubes", part 116, 2004. 